\title{
Autoria em produções científicas: conceitos, critérios, integridade na pesquisa e responsabilidade na colaboração
}

\author{
Juliana Soares Lima* \\ Maria Giovanna Guedes Farias**
}

\footnotetext{
Artículo recibido:

8 de enero de 2019

Artículo aceptado:

14 de mayo de 2019
}

Artículo de revisión
Resumo

Objetiva discutir a autoria científica, conceitos e critérios relacionados à responsabilidade dos autores em suas contribuições, além de vislumbrar aspectos éticos e de integridade na pesquisa à luz da comunicação científica. Realizou-se uma revisão de literatura com a finalidade de buscar e levantar referências sobre o tema. Os materiais selecionados tiveram como critério principal a procedência das fontes científicas, tais como livros e artigos científicos, além de alguns sites de entidades oficiais que estabelecem normas e critérios para a atribuição de autoria. Os resultados demonstram que os conceitos de autor, autoria, coautor e colaborador ainda não possuem uma definição única

* Universidade Federal do Ceará, Centro de Humanidades I, Brasil

julia10br@gmail.com

** Universidade Federal do Ceará, Centro de Humanidades II, Brasi

mgiovannaguedes@gmail.com

INVESTIGACIÓN BIBLIOTECOLÓGICA, vol. 34, núm. 82, enero/marzo, 2020, México, ISSN: 2448-8321 pp. 103-139 
e que englobe todo o conjunto de critérios que constituem a autoria. Conclui-se que os pesquisadores podem criar um conjunto de diretrizes para definir suas contribuições e tarefas, além de optarem pela adoção de modelos ou políticas de autoria sugeridas por sua área, instituição ou pelos periódicos científicos, a fim de evitar problemas relacionados à escrita colaborativa e em artigos com múltiplas autorias.

Palavras-chave: Autoria; Coautoria; Integridade na Pesquisa

Autoría en producciones científicas: conceptos, criterios, integridad en la investigación y responsabilidad en la colaboración

Juliana Soares Lima y Maria Giovanna Guedes Farias

\section{RESUMEN}

Este artículo tiene el objetivo de discutir la autoría científica y los conceptos y criterios relacionados con la responsabilidad de los autores respecto de sus contribuciones; además de pretender vislumbrar los aspectos éticos y de integridad que se suscitan en la investigación y la comunicación científica. Una revisión de la literatura sobre el tema se hizo con la finalidad de buscar y obtener referencias. Los materiales seleccionados obedecieron al criterio principal de averiguar la procedencia de las fuentes científicas, tales como los libros y artículos científicos, además de algunos otros sitios de entidades oficiales que establecen normas y criterios para establecer la atribución de la autoría. Los resultados demuestran que los conceptos de autor, autoría, coautor y colaborador todavía no poseen una definición única y que englobe todo el conjunto de los criterios que constituyen la autoría. Se concluye que los investigadores pueden crear un conjunto de directrices para definir sus contribuciones y tareas, y todavía optar por la adopción de modelos o políticas de autoría sugeridos por su área, institución o por los periódicos científicos a fin de evitar los problemas relacionados con la escritura colaborativa y los artículos de autoría múltiple.

Palabras clave: Autoría; Co-autoría; Integridad en la Investigación 
Authorship in scientific productions: concepts, criteria, integrity in research and responsibility in collaboration Juliana Soares Lima and Maria Giovanna Guedes Farias

\section{Abstract}

This article aims to discuss the scientific authorship, the concepts and the criteria related to the responsibility of authors regarding their contributions, as well as to glimpse over the ethical and integrity aspects of research in scientific communication. A literature review was carried out with the purpose of seeking and raising references on the subject. The selected materials had as main criterion the origin of the scientific sources, such as books and scientific articles, besides some sites of official entities that establish norms and criteria for the attribution of authorship. The results demonstrate that the concepts of author, authorship, coauthor and collaborator do not yet have a single definition and that encompasses the whole set that contemplates the criteria that constitute authorship. It is concluded that researchers can create a set of guidelines to define their contributions and tasks, or they can choose to adopt models or policies of authorship suggested by their area, institution or scientific journals for avoiding problems related with collaborative writing and articles with multiple authorships.

Keywords: Authorship; Co-authorship; Research Integrity

\section{INTRODUÇÃO}

cultura oral e a transmissão de conhecimento por meio de narrativas
prevaleceram por muito tempo e sobrepujaram a escrita. Com a prática da cópia e anotação dos discursos como forma de conservar a memória, e mais tarde com o surgimento da imprensa, a noção de propriedade privada e do direito autoral tornou-se uma necessidade premente. A autoria baseada na criação de uma obra escrita tem sido objeto de estudo primordialmente na Linguística, seguida das áreas de Filosofia, Historiografia e Psicanálise, debatida por autores como Barthes (1988) em sua anunciada 'morte do autor'; Bakhtin (2011) e sua comunicação dialógica do autor com os textos; Foucault 
(1992) e a função do autor, e, por fim, Lacan (1985) e a dimensão escrita na psicanálise através do conceito de letra, adentrando, inclusive, em discussões sobre ideograma para apresentar sua teoria do significante e significado.

No domínio da comunicação científica e em outras áreas, muito se discute a respeito da autoria e suas implicações; entretanto, faz-se necessário contrapor vários conceitos sobre o que caracteriza a autoria e quais são os critérios a serem cumpridos para ser considerado um autor. Há perspectivas diferentes em relação à figura do autor enquanto escritor ou se esta seria uma função distinta, por exemplo, do autor que escreve um romance e outro que redige um artigo científico.

Essas potenciais diferenças entre autoria científica e literária já foram debatidas por Charles Percy Snow, no livro The Two Cultures, tendo sido o primeiro a elaborar este conceito em meados de 1959. Snow (1956) discutiu a clara separação e hostilidade entre essas duas culturas e sobre a divisão entre os cientistas e os intelectuais escritores. Um século antes de Snow, em 1828, a Yale College publicou um relatório que debatia o choque de culturas acadêmicas no ensino superior americano.

Para além da escrita, a autoria permeia outras esferas da criação: um escultor é o autor de sua obra de arte, no entanto, ele não a escreve e nem a representa por meio de signos, a molda e esculpe. Igualmente o fotógrafo e seus produtos gerados a partir de um olhar estético e apurado para capturar um dado momento no espaço-tempo: as fotografias. As telas pintadas por famosos artistas como Monet, Renoir, Rembrandt, Tarsila do Amaral e tantos outros são 'criações do espírito' e de expressão autoral artística. As pinturas rupestres, encontradas nas cavernas, são registros do passado, não são consideradas tecnicamente como obras de arte, nem utilizam a escrita como a conhecemos hoje, são imagéticas, porém, foram criadas pelos homens pré-históricos e, ainda assim, são consideradas patrimônio histórico e cultural da humanidade. Outro exemplo semelhante são os hieróglifos egípcios estampados em inúmeras pirâmides e obras arquitetônicas do Egito. Finalmente, não podemos deixar de citar as produções cinematográficas e seus tantos papéis desenvolvidos na autoria (diretor, produtor, roteirista etc.) e abertos para discussão até o momento por não terem um conceito fechado.

Assim sendo, a autoria em si é uma criação do homem, advém da Idade Média, perpassa a invenção da imprensa de Gutenberg e existe até os dias atuais. Outrossim, a autoria constitui diferentes formas de expressão encontradas pelo homem, seja pela escrita, escultura, linguagem ou qualquer outra. A partir destas reflexões, apresentamos neste artigo uma revisão de literatura que tem como objetivo discutir a autoria científica, assim como os conceitos e critérios relacionados à responsabilidade dos autores em suas contribuições, além de vislumbrar aspectos éticos e de integridade na pesquisa. 
A revisão de literatura, também conhecida como revisão bibliográfica, consiste na contextualização de um problema e análise de aspectos já descritos e presentes na literatura científica a fim de construir o referencial teórico de uma pesquisa e buscar referências sobre o tema (Alves-Mazzotti, 2002; Cervo e Bervian, 2002). Para subsidiar a referida revisão, realizou-se um levantamento bibliográfico com o auxílio do software Publish or Perish (PoP) com o intuito de levantar as principais fontes sobre o assunto. Além disso, o PoP recupera e analisa citações através de seis fontes de dados, a saber: Crossref, Google Scholar, Google Scholar Profile, Microsoft Academic, Scopus e Web of Science.

Os materiais selecionados para este estudo tiveram como critério principal a procedência das fontes científicas formais, tais como livros e artigos científicos, além de alguns sites de entidades oficiais que estabelecem normas e critérios para a atribuição de autoria, oportunizando a construção de um quadro teórico e a análise do estado da arte sobre a temática. Elias et al. (2012) afirma que esse tipo de investigação permite identificar novas temáticas, apontar novas perspectivas, estabelecer relações com a literatura existente, o que contribui para a consolidação de uma área do conhecimento.

\section{Autoria: Reflexões}

A palavra 'autor' origina-se do latim 'Auctor': o que aumenta, fundador, mestre, líder, ou ainda "o que faz crescer" (auctus, particípio passado de augere, que significa aumentar). Outro significado atribuído à origem da palavra provém do século XIV: aquele que emite ordens por escrito.

$\mathrm{Na}$ perspectiva de Bakhtin (2011: 308), "Todo texto tem um sujeito, um autor (o falante, ou quem escreve)" e, assim sendo, reforça o sistema de linguagem por trás de cada texto, seja ele oral ou escrito. Bakhtin (2011) descontruiu, ainda, a visão tradicional de autoria e estabeleceu diferentes tipos de classificação para o autor, fazendo uma cisão entre autor-pessoa e autor-criador. Nesse sentido, Bakhtin analisa a autoria em obras literárias sob um viés filosófico da linguagem, enfatizando a relação do eu com o outro, conduzindo as discussões inclusive para a criação artística, pari passu em que descortina a dinâmica social do cotidiano e sua influência na vida dos indivíduos.

Baseado na teoria Linguística para discutir autoria, sua natureza, função, além de analisar a noção de texto e destacar a importância do leitor em dar sentido à obra do escritor literário, Barthes (1988) afirma que o autor é uma invenção positivista da sociedade moderna e classifica a autoria em duas funções: escritor e escrevente. O escritor é comparado a um sacerdote, utiliza 
a linguagem escrita com finalidade estética e estilística, ao passo que o escrevente utiliza a palavra como instrumento de comunicação, um meio para manifestar seu pensamento.

Conforme Certeau (2014: 269-270), “[...] a escritura só tem sentido fora de si mesma, num lugar outro, o do leitor [...]. Vai em direção a uma palavra que não lhe jamais será dada e que, por isso mesmo, constrói o movimento de ser indefinidamente ligada a uma resposta solta, absoluta, a do outro".

Chartier (2009: 32) afirma que "Para que exista autor são necessários critérios, noções, conceitos particulares". O autor apresenta a noção de writer (aquele que escreve) e author (aquele cujo nome dá identidade e autoridade ao texto) em inglês. Em francês, écrivain (escritor) é aquele que escreveu um texto que ainda não está em circulação, enquanto que auteur (autor) é qualificado como alguém que publicou obras impressas.

Chartier (2009) afirma que a cópia de trabalhos era muito comum, assim, tornou-se uma preocupação a questão da proteção jurídica ao trabalho do autor no século XV, com a invenção da imprensa e com a prática da cópia de textos como uma atividade de massa. Christofoletti (2006), por sua vez, afirma que, na Idade Média, o termo 'autor' era empregado àquele que tinha autoridade, ou seja, este não estava exatamente relacionado a quem escrevia, mas sim a quem dominava determinado assunto.

Para Orlandi (2004), autor é aquele que se responsabiliza por aquilo que diz e escreve. Por seu turno, Lunsford e Ede (1990: 20) declaram que "Escrever é um ato social”. Bianchetti, Zuin e Ferraz (2018: 150-151) veem a autoria como "[...] uma trama que envolve muitos fios, os quais não são transparentes; ao contrário, são de muitas cores e marcados pelas subjetividades dos sujeitos envolvidos, têm a forma da trajetória de sua história, de suas idiossincrasias e das experiências que vivenciam na dimensão coletiva".

Além da subjetividade de que tratam os autores, as influências de cada indivíduo em relação à sua leitura de mundo, experiências e repertório, os autores supracitados chamam a atenção para o aspecto relativo às contribuições individuais e coletivas, e que estas interferem na responsabilidade e escolha do autor principal e coautores. Ligado a esse fato, outro ponto que reverbera na autoria é o próprio ato de escrever, pois este pressupõe a fala, o discurso, a escrita e até mesmo o ato de ler. Seguindo esta linha de pensamento, de acordo com Foucault (1992), a leitura proporciona a apropriação do discurso do autor lido, o que pode refletir em sua escrita e forma de pensar, mas o ato de escrever não o torna necessariamente um autor. Dessa maneira, Foucault (1992) inaugura o conceito de função do autor e esclarece que autor e autoria podem não ser iguais, embora estes não possam se dissociar: 
[...] quando se fala de autoria, pensa-se em alguma manifestação peculiar relacionada à escrita; [...] não se pode imaginar que alguém seja autor, se seus textos não se inscreveram em discursos, ou seja, em domínios de memória que façam sentido; por fim, creio que nem vale a pena tratar de autoria sem enfrentar o desafio de imaginar verdadeira a hipótese de certa pessoalidade, de alguma singularidade. (Foucault, 1992: 17)

Para Foucault (2005), a autoria é uma função discursiva e ganhou destaque quando os discursos se tornaram transgressores, passando a caracterizar a ligação intrínseca entre a existência, a circulação e o funcionamento de discursos dentro da sociedade. Assim, ele nos conduziu a uma reflexão sobre os elementos que estabelecem a autoria, de tal modo que a figura do autor se desdobra, os escritos se multiplicam e as diferenças entre autor literário e autor científico são colocadas em xeque.

Assim, Chartier (2012), um dos maiores estudiosos sobre a autoria e a história do livro, demonstra que a história do autor científico é indissociável da história cultural da ciência ao discorrer sobre as correlações históricas entre o nome do autor, a assinatura (a partir do século XVIII passou a ter o significado de autoria de um texto ao nome de um autor individual), a figura do editor, além de esboçar a caracterização do autor científico e do autor literário. Devemos considerar que, nesse período, a cultura oral prevalecia sobre a escrita e a transmissão dos conhecimentos acumulados era realizada de maneira narrativa e interpretativa.

Dando prosseguimento ao liame da autoria com a comunicação científica, recorremos a Meadows (1999), que esclarece não haver exatidão em relação ao início da comunicação científica; entretanto, os gregos são creditados por instituir a tradição desta área e da pesquisa por meio da fala e escrita.

O termo 'comunicação científica' foi cunhado pelo físico John Desmond Bernal em 1939, que define a comunicação científica como um amplo processo de geração, transferência e uso de informação científica. Para Garvey (1979), a comunicação científica é definida como a troca de informações entre os membros da comunidade científica, incluindo as atividades associadas à produção, disseminação e uso da informação, desde o momento em que o cientista concebe uma ideia para a sua pesquisa até que esta seja aceita pelos pares.

A comunicação científica situa-se, conforme Meadows (1999: vii), "no próprio coração da ciência. É para ela tão vital quanto à própria pesquisa, pois a esta não cabe reivindicar com legitimidade este nome enquanto não houver sido analisada e aceita pelos pares". Por isso, é fundamental que os resultados provenientes de pesquisas científicas sejam comunicados.

A autoria científica está diretamente relacionada à comunicação científica, desde os tempos em que os cientistas se correspondiam através de cartas e, posteriormente, marcavam encontros regulares para debater ideias e 
descobertas. Com o estabelecimento dos colégios invisíveis e das sociedades científicas, a criação dos periódicos científicos propiciou a publicação desses estudiosos com o intuito de divulgar as suas descobertas entre os seus pares.

Sobre o colégio invisível, é definido por vários autores como um grupo de pesquisadores que trabalham juntos em determinado problema ou área de pesquisa, geograficamente dispersos, que trocam informações e mantêm contato frequente sobre o andamento das pesquisas que desenvolvem em comum (Acosta-Hoyos, 1980; Crane, 1988; Meadows, 1999; Merton, 1977; Mueller, 1994).

Complementando a definição de colégio invisível, Merton (1977) esclarece que a referida expressão foi cunhada por Robert Boyle, cientista inglês que viveu no século XVII. O termo foi originalmente empregado para descrever um grupo de pesquisadores que mantinham contato entre si, apesar da distância geográfica e de suas diferentes instituições. Esse mesmo grupo descrito por Boyle mais tarde tornou-se a Royal Society of London. Merton adicionou ainda o fato de Price ser um dos autores que reinventou a expressão colégio invisivel, chamando-a de 'novos colégios invisíveis'.

Retomando a discussão sobre o tema deste artigo, Krokoscz (2015: 90) argumenta que a autoria científica é bastante específica, trata-se de "[...] uma modalidade autoral típica dos processos de produção textual acadêmica, a qual pode ser exemplificada em editoriais, resumos, pôsteres, artigos, capítulos [...] e livros [...]".

Outra característica da autoria científica é a coautoria. Hilário, Grácio e Guimarães (2018: 17-18) consideram “[...] coautores aqueles que participam intensamente da elaboração da pesquisa e assumem a responsabilidade do seu conteúdo, por meio da assinatura conjunta do trabalho, de modo que possam, em qualquer instância, apresentar e defender a ideia original do trabalho".

Meadows (1999) destaca que a autoria coletiva tem aumentado nos últimos anos, afinal, muitos trabalhos científicos têm sido escritos em colaboração, o que dá maior visibilidade à pesquisa, considerando o número de citações que recebem, e, conforme o referido autor, pesquisas em colaboração tendem a ter melhor qualidade, já que estão envolvidos cientistas produtivos, renomados e de prestígio.

Para Targino (2010), não há mais como pensar em autoria única, pois a responsabilidade e o mérito do trabalho científico são divididos, a diferença entre autor e coautor está circunscrita à liderança no encaminhamento das atividades, e não na responsabilidade autoral.

A respeito da definição de autoria, o Committee on Publication Ethics (COPE) apresenta uma visão ampla e completa, que inclui responsabilidades, direitos e deveres concernentes à ética e integridade, tanto de qualquer 
pesquisa acadêmica como também se aplica a outros tipos de criações relacionadas à autoria:

O termo autoria pode se referir ao criador de uma ideia (por exemplo, o autor da teoria da relatividade) ou ao indivíduo ou individuos que desenvolvem e realizam o produto que dissemina obras intelectuais ou criativas (por exemplo, o autor de uma ideia, poema ou um artigo acadêmico). [...] No mínimo, os autores devem garantir que fizeram o trabalho conforme apresentado e que não violaram os direitos legais [...] no processo. (COPE, 2014: 1, tradução nossa, grifo nosso)

$\mathrm{Na}$ esteira desse pensamento, Biagioli (2003) diferencia a autoria científica de outros tipos pelo fato de ter como característica principal a recompensa moral, além disso, o autor científico não recebe nenhum retorno financeiro por suas produções, levando em consideração que a sua recompensa não é dada por nenhuma nação e suas leis, mas pela comunidade internacional - os pares. Então, a autoria científica é, antes de tudo, uma doação, uma contribuição do pesquisador para a ciência e a humanidade.

Remontando aos ideais do sociólogo Mauss (2003), em seu 'Ensaio sobre a dádiva', o conhecimento científico é um presente; portanto, deve ser compartilhado. Sob esse viés, Suber (2007: 194, tradução nossa) reforça que "O conhecimento não é uma mercadoria (assim como os fatos não são protegidos por direitos autorais)", consequentemente, o conhecimento é uma dádiva, deve estar disponível para as pessoas como um bem público. $\mathrm{O}$ autor científico participa da economia da dádiva, desprovido de interesse econômico, por conseguinte, não poderia ser reduzido a um bem patrimonial ou mercantilizado, afinal, a autoria científica faz parte de um sistema de trocas que visa à reciprocidade, reputação e responsabilidade. Nas palavras de Bourdieu (2001), é o capital construído no conhecimento e reconhecimento.

Desrochers et al. (2018) complementam essa visão à luz do capital simbólico de Bourdieu e acrescentam que o sistema de recompensas da ciência mudou, passando a competir com novos meios de disseminação, avaliação e impacto acadêmico. São eles: a autoria, as citações, os agradecimentos, o reconhecimento do pesquisador e o uso cada vez mais crescente de mídias sociais acadêmicas, dentre elas: Academia.edu, Mendeley e ResearchGate, além do microblog Twitter e outras plataformas digitais para a divulgação e visibilidade dos cientistas. A partir desses aspectos, os autores se apoiam em Cronin $(2001 ; 2015)$ para explicar que o conceito de autoria historicamente não foi bem definido, assim como enfrenta mudanças em sua definição na academia, especialmente nos últimos anos.

Oliveira (2009: 291) afirma que "[...] o principal objetivo de um cientista é produzir novos conhecimentos e que a divulgação de suas descobertas 
aumenta as oportunidades de circulação desses novos conhecimentos [...]”. A autora acrescenta que é fundamental contribuir com esse processo porque atende ao caráter cumulativo da ciência e suas regras fundamentais para assegurar a originalidade e prioridade.

Por esse prisma, é esperado do autor o ineditismo e a originalidade, apesar de ser praticamente impossível em manuscritos acadêmicos e na comunicação científica escrever livremente e sem citação, ou ao menos a menção de qualquer fonte, tendo em vista que os autores devem dar os devidos créditos a outros que o precederam.

Sobre isso, recordemos Isaac Newton, famoso pela sua frase: "Se enxerguei mais longe foi porque me apoiei nos ombros de gigantes". Esse aforismo tornou-se bastante conhecido na literatura científica, sendo, inclusive, citado na obra 'Comunicação científica', de Meadows (1999), além de ter inspirado a obra 'On the shoulders of giants', do sociólogo Merton (1993). Nesta, discutem-se: a tradição na pesquisa; o plágio; a transmissão do conhecimento; o conceito de progresso social da ciência e sobre questões mais profundas: a criatividade, a originalidade, o contexto social da descoberta etc. e ainda mais na visão foucaultiana, como "[...] dizer pela primeira vez aquilo que, entretanto, já havia sido dito e repetir incansavelmente aquilo que, no entanto, não havia jamais sido dito?" (Foucault, 2005: 25).

No texto científico, os autores devem se embasar nos fatos, fontes e dados para sustentar seus argumentos, e uma das formas de se fazer isso é o uso de citações. A linguagem deve ser clara, concisa, objetiva, sem vieses ou juízos de valor. Por outro lado, a autoria literária trabalha no contexto da intertextualidade, na qual não há a obrigatoriedade de citar outros autores de maneira explícita. A escrita literária possui conteúdo poético, repleto de sentimentalismo, subjetivismo e utiliza linguagem conotativa. $\mathrm{Na}$ área da Linguística, a intertextualidade é um recurso utilizado nos textos e, embora utilize trechos semelhantes, proporciona um diálogo entre as duas obras e estabelece uma analogia ou referência entre os textos (escrito ou visual), denotando a clara fonte de inspiração e alusão ao autor ou texto.

\section{CARACTERÍSTICAS E CRITÉRIOS DA AUTORIA}

Na década de 90, de acordo com Rennie, Yank e Emanuel (1997) e Yank e Rennie (1999), como resposta às dificuldades de definir autoria na ciência, alguns interessados e editores científicos começaram a defender um modelo baseado na contribuição, isto é, os artigos publicados incluem uma lista de colaboradores ao invés de elencar autores e criar uma seção de agradecimen- 
tos para informar a identidade daqueles que contribuíram com o trabalho, mas que não se qualificaram como autor.

Muitos editores defendem esse modelo com o argumento de que seria uma maneira mais transparente, justa e definida de se manter bem informados sobre as reais contribuições dos autores e de suas responsabilidades públicas pelo conteúdo do manuscrito, fazendo com que os autores descrevam exatamente o que cada autor fez durante o início, meio e fim do estudo até a sua publicação. O problema desse modelo é que os autores designam um papel funcional dentro do grupo e nem sempre estão qualificados para assegurar a autoria, acarretando problemas como o aparecimento de uma série de autorias inapropriadas.

Por esse viés, os critérios do International Committee of Medical Journal Editors (ICMJE), também conhecidos como 'normas de Vancouver', fornecem orientações sobre os tipos de contribuições que caracterizam os indivíduos que colaboraram o suficiente para ganhar a designação 'autor'. $\mathrm{O}$ ICMJE "reconhece que a autoria em si não discrimina quais os tipos de contribuições qualificam cada indivíduo para ser autor", por isso, reitera que os editores devem desenvolver e implementar uma política de autoria, a fim de dirimir qualquer ambiguidade quanto às contribuições. Conforme as recomendações do ICMJE, que visam à garantia do crédito como autores aos que colaboraram com contribuições intelectuais substanciais para o trabalho, a autoria confere crédito ao trabalho, traz importantes implicações acadêmicas, sociais e financeiras, significa dever e responsabilidade por aquilo que se publica (ICMJE, 2019).

De acordo com Pereira (2011: 158), “A presença do nome do autor tem a finalidade de assegurar a propriedade intelectual da obra. [...] O seu nome, passando a ser respeitado, confere credibilidade ao que diz ou publica”. Segundo ele, os leitores terão o autor como guia a fim de realizar uma busca e rastrear a boa literatura científica, fazendo com que isso pese na seleção de seu material de leitura, conforme expresso a seguir (Quadro 1):

\begin{tabular}{|l|l|}
\hline Assegurar & a propriedade intelectual da obra. \\
\hline Auxiliar & o leitor na seleção de material para leitura. \\
\hline Avaliar & a produção científica de autores. \\
\hline Acompanhar & a citação de um artigo. \\
\multicolumn{2}{|c|}{ Quadro 1. Para que serve a autoria } \\
\end{tabular}


O ICMJE reconhece que as questões sobre a quantidade e a qualidade das contribuições que qualificam um indivíduo como autor não resolvem completamente o problema da autoria. Assim, estabeleceram-se 4 (quatro) critérios básicos para que a autoria possa ser considerada, incluindo-se aqueles que distinguem autores de outros colaboradores, apresentadas no Quadro 2:

\begin{tabular}{|l|l|}
\hline 1. & $\begin{array}{l}\text { Contribuições substanciais para concepção e delineamento, coleta, de dados ou análise } \\
\text { e interpretação dos dados. }\end{array}$ \\
\hline 2. & $\begin{array}{l}\text { Elaboração, redação, revisão crítica e versões preliminares do artigo em relação ao conteúdo } \\
\text { intelectualmente importante. }\end{array}$ \\
\hline 3. & Aprovação final da versão a ser publicada. \\
\hline 4. & $\begin{array}{l}\text { Concordância em ser responsável por todos os aspectos do trabalho, no sentido de garantir que as } \\
\text { questões relacionadas à exatidão ou à integridade de qualquer parte da obra sejam devidamente } \\
\text { investigadas e resolvidas. }\end{array}$ \\
\hline
\end{tabular}

Quadro 2. Critérios para autoria ICMJE

Fonte: baseado em Pereira (2011: 160) e nas Normas de Vancouver

Entre esses quatro critérios, o primeiro é bastante específico e demonstra desde já qual é a característica considerada a mais importante para o ICMJE na atribuição do status de autor. Targino (2010) coaduna com essa visão, estabelecendo, inclusive, definição muito semelhante aos quatro critérios do ICMJE:

Autor e coautores devem colaborar em todas as etapas. Estas compreendem a concepção da ideia, a delimitação do objeto de estudo, a consecução dos objetos pretendidos, além do estabelecimento da linha teórica adotada. Abrangem, ainda, a decisão dos procedimentos metodológicos, análise e respectiva interpretação dos dados coletados até a elaboração preliminar e final do texto que sumariza resultados e conclusões obtidas. (Targino, 2010: 146)

Além do ICMJE, outras diversas áreas costumam estabelecer normas nacionais e internacionais, requisitos básicos para seus manuscritos, como orientações para os autores, não se prendendo apenas ao aspecto da forma, mas também em recomendações para a escrita científica, tratando, inclusive, das questões éticas, de responsabilidade e dos critérios de autoria e coautoria (Anexo A), a exemplo das áreas de Antropologia, Ciências Sociais, Direito, Física, Medicina, Psicologia, entre outras entidades que divulgam essas informações em seus websites (Anexo B).

Outro aspecto que costuma causar determinados problemas é a ordem de autoria. Vários autores discorreram sobre as práticas de ordenação dos nomes de autores em artigos e publicações científicas, e, geralmente, os costumes variam de acordo com cada área do conhecimento. Alguns autores são 
listados em ordem de importância e de contribuição, entretanto, algumas áreas adotam a ordem alfabética por prenome ou sobrenome (Biagioli, 2003; Costas e Bordons, 2011; Larivière et al., 2016; Pontille, 2004; Waltman, 2012; Zuckerman, 1968).

Sobre a ordem alfabética em autoria, Waltman (2012) realizou um estudo incluindo todas as áreas do conhecimento e demonstrou em seu artigo o declínio dessa prática e a adoção da atribuição de ordenação dos autores por contribuição, afinal, em ordem alfabética, não é possível inferir qual o grau de envolvimento e participação efetiva de cada um dos responsáveis pelo manuscrito, enquanto que a ordem de contribuição já permite visualizar o que fez cada autor.

Costas e Bordons (2011) realizaram um estudo bibliométrico sobre a ordem de autoria nas áreas de Biologia, Biomedicina, Ciência dos Materiais e Recursos Naturais, e constataram que a idade, a posição hierárquica profissional e o perfil bibliométrico dos cientistas influenciam a ordem de autoria e o nível de colaboração.

Segundo Pereira (2011: 160), “Nem sempre é fácil separar os nomes dos que devem ser incluídos como autores daqueles que ficam melhor situados na seção de agradecimentos ou que não aparecem em uma ou outra categoria, embora tenham contribuído para o andamento da pesquisa”. $\mathrm{Na}$ verdade, a ordem de autoria deve ser uma decisão conjunta, acertada com antecedência e já no início do projeto de escrita, apesar de não existir uma orientação exata sobre isso.

Para os autores principais com o mesmo grau de colaboração, Volpato (2016: 114) indica que podem ser sinalizados: "Algumas vezes, dois ou mais autores se consideram com o mesmo nível de participação no trabalho. Isso é possível e deve ser honestamente acertado entre os autores, mesmo que numa fase mais avançada do artigo".

Destacamos, ainda, o projeto Contributor Roles Taxonomy (CRediT, https://casrai.org/credit/): trata-se de uma taxonomia de alto nível e inclui 14 papéis que podem representar os autores e colaboradores em típicas funções desempenhadas por eles na produção acadêmica científica (Quadro 3). O CRediT foi criado pelo Consortia Advancing Standards in Research Administration Information (Casrai, https://casrai.org/), uma iniciativa internacional e associação sem fins lucrativos liderada por instituições de pesquisa.

\begin{tabular}{|c|l|l|}
\hline$\#$ & \multicolumn{1}{|c|}{ Função } & \multicolumn{1}{c|}{ Definição } \\
\hline 1 & Conceituação & $\begin{array}{l}\text { Ideias; formulação ou evolução de metas e objetivos de pesquisa } \\
\text { abrangentes. }\end{array}$ \\
\hline
\end{tabular}




\begin{tabular}{|c|c|c|}
\hline 2 & Curadoria de dados & $\begin{array}{l}\text { Atividades de gerenciamento para anotar (produzir metadados), pro- } \\
\text { cessar e limpar dados e manutenção dos dados de pesquisa (incluindo } \\
\text { código de software, onde é necessário para interpretar os dados em si) } \\
\text { para uso inicial e posterior reutilização. }\end{array}$ \\
\hline 3 & Análise formal & $\begin{array}{l}\text { Aplicação de técnicas estatísticas, matemáticas, computacionais ou } \\
\text { outras técnicas formais para analisar ou sintetizar dados do estudo. }\end{array}$ \\
\hline 4 & $\begin{array}{l}\text { Aquisição de financia- } \\
\text { mento }\end{array}$ & $\begin{array}{l}\text { Aquisição do suporte financeiro para o projeto que conduz à publi- } \\
\text { cação. }\end{array}$ \\
\hline 5 & Investigação & $\begin{array}{l}\text { Condução do processo de pesquisa e investigação, especialmente a } \\
\text { execução dos experimentos ou coleta de dados / evidências. }\end{array}$ \\
\hline 6 & Metodologia & Desenvolvimento ou desenho de metodologia; criação de modelos. \\
\hline 7 & $\begin{array}{l}\text { Administração de } \\
\text { projetos }\end{array}$ & $\begin{array}{l}\text { Responsável pela gestão e coordenação do planejamento e execução } \\
\text { da atividade de pesquisa. }\end{array}$ \\
\hline 8 & Recursos & $\begin{array}{l}\text { Fornecimento de materiais de estudo, reagentes, materiais, pacientes, } \\
\text { amostras de laboratório, animais, instrumentação, recursos de com- } \\
\text { putação ou outras ferramentas de análise. }\end{array}$ \\
\hline 9 & Software & $\begin{array}{l}\text { Programação, desenvolvimento de software; concepção de programas } \\
\text { de computador; implementação do código de computador e algoritmos } \\
\text { de suporte; teste de componentes de código existentes. }\end{array}$ \\
\hline 10 & Supervisão & $\begin{array}{l}\text { Responsável pela supervisão e liderança do planejamento e execução } \\
\text { da atividade de pesquisa, incluindo orientação externa à equipe } \\
\text { principal. }\end{array}$ \\
\hline 11 & Validação & $\begin{array}{l}\text { Verificação, seja como parte da atividade ou separada, da replicação / } \\
\text { reprodutibilidade geral de resultados / experimentos e outros resulta- } \\
\text { dos de pesquisa. }\end{array}$ \\
\hline 12 & Visualização & $\begin{array}{l}\text { Preparação, criação e / ou apresentação do trabalho publicado, espe- } \\
\text { cificamente visualização / apresentação de dados. }\end{array}$ \\
\hline 13 & $\begin{array}{l}\text { Escrita - rascunho } \\
\text { original }\end{array}$ & $\begin{array}{l}\text { Preparação, criação e / ou apresentação do trabalho publicado, espe- } \\
\text { cificamente escrevendo o rascunho inicial (incluindo a tradução). }\end{array}$ \\
\hline 14 & $\begin{array}{l}\text { Escrita - revisão e } \\
\text { edição }\end{array}$ & $\begin{array}{l}\text { Preparação, criação e / ou apresentação do trabalho publicado pelo } \\
\text { grupo de pesquisa, especificamente revisão crítica, comentário ou } \\
\text { revisão - incluindo as fases pré ou pós-publicação. }\end{array}$ \\
\hline
\end{tabular}

Quadro 3. 14 funções de contribuição desempenhadas na produção científica Fonte: CRediT, 2018

O Casrai ${ }^{1}$ tem como missão adaptar os princípios e as melhores práticas de padrões abertos e governança de dados, inclusive cobre todos os principais requisitos de informação relacionados ao gerenciamento de uma pesquisa ao longo de seu ciclo de vida, incluindo os requisitos de informação relacionados aos pedidos de financiamento, currículos, gerenciamento de projetos, requisitos de conformidade, relatórios, gerenciamento de dados de pesquisa 
e comunicações acadêmicas. A iniciativa oferece, ainda, um dicionário (https://dictionary.casrai.org/Main_Page), que contém termos relacionados à informação de gestão de pesquisas.

A taxonomia de papéis com a finalidade de atribuir quais foram as contribuições de cada pesquisador em determinado estudo inclui essas informações nos metadados do artigo, além disso, exige que os autores usem o Open Researcher and Contributor ID (Orcid, https://orcid.org), um identificador digital persistente para autores. Segundo o Casrai, o CRediT nasceu a partir da seguinte compreensão:

[...] as convenções bibliográficas para descrever e listar os autores sobre os resultados acadêmicos estão cada vez mais ultrapassadas e não representam o leque de contribuições que os pesquisadores fazem ao resultado publicado. Além disso, há um interesse crescente entre pesquisadores, agências financiadoras, instituições acadêmicas, editores e editores em aumentar a transparência e a acessibilidade das contribuições de pesquisa. (Consortia Advancing Standards In Research Administration Information, 2018, online)

Muitos editores científicos e financiadores passaram a exigir declarações sobre o papel desempenhado pelos autores e sua contribuição na submissão de artigos. Em 2012, a Wellcome Trust e a Harvard University foram anfitriões de um workshop sobre os modelos de contribuição e atribuição alternativos para autoria científica. O referido evento gerou um relatório, ${ }^{2}$ elaborado inicialmente por um grupo de editores científicos, principalmente os membros do ICMJE, e então foi estabelecido o projeto piloto para desenvolver um vocabulário controlado de funções de contribuição que pudesse descrever os diversos tipos de contribuições na produção acadêmica publicada. O projeto de taxonomia foi testado, bem recebido pela comunidade científica e seus resultados foram descritos em uma edição da Revista Nature, ${ }^{3}$ em abril de 2014. Desde então, o projeto CRediT tem sido amplamente adotado por muitas revistas científicas.

O Casrai esclarece que as funções propostas na taxonomia não estão limitadas às funções tradicionais de autoria e alertam que os papéis não pretendem definir o que constitui autoria. Portanto, pretende especificar o trabalho do que cada um dos envolvidos fez de tal forma que permita às publicações acadêmicas divulgarem aos leitores essa informação. Não obstante, as recomendações para a adoção da taxonomia do CRediT são:

2 Report on the International Workshop on Contributorship and Scholarly Attribution: https:// projects.iq.harvard.edu/files/attribution_workshop/files/iwcsa_report_final_18sept12.pdf

3 Credit where credit is due: https://www.nature.com/polopoly_fs/1.15033!/menu/main/topColumns/topLeftColumn/pdf/508312a.pdf 
a) Listar todas as contribuições, inclusive daqueles que constarem nos agradecimentos;

b) Informar os múltiplos papéis desempenhados;

c) Descrever o grau de contribuição opcional;

d) Esclarecer para os autores que a responsabilidade é compartilhada;

e) Tornar o CRediT interoperável e legível por máquina por meio da codificação da Extensible Markup Language (XML) no padrão Journal Article Tag Suite (JATS), formalmente conhecido como ANSI NISO Z39.96-2015, um conjunto de tags XML, ${ }^{4}$ um padrão internacional para artigos de periódicos.

Diante do panorama apresentado até aqui, após confrontar diversas visões de autores como Foucault, Chartier e vários outros autores, do mesmo modo Monteiro et al. (2004), Montenegro e Alves (1987) e Petroianu (2010) discorreram sobre o tema e tentaram estabelecer critérios e pontuações para definir a ordem de autoria em um manuscrito conforme o grau de envolvimento e participação no processo de escrita, nas tarefas realizadas, em coletas de dados, na contribuição substancial etc. Entretanto, esse não é um assunto simples e está longe de ser resolvido, afinal, pode implicar em desavenças entre os participantes membros de um mesmo projeto. Então, consequentemente, ocorrem alguns abusos relacionados à autoria e muitas questões éticas são levantadas.

\section{INTEGRIDADE CIENTÍFICA E SUAS RELAÇÕES COM A AUTORIA}

A integridade da pesquisa científica e a autoria estão entrelaçadas, afinal, ambas dependem da boa conduta, da ética e do respeito. Isto posto, é compreensível que alguns documentos normativos e recomendações tenham sido elaborados ao longo dos anos a fim de nortear a conduta científica de pesquisadores.

Antes de discorrer acerca de alguns casos relacionados à autoria, é necessário discutir, em linhas gerais, certos princípios éticos. O termo 'ética' (ethos) tem origem no grego, está relacionado ao caráter e diz respeito à reflexão sobre os nossos atos morais (Valls, 2008). Nesse sentido, Aristóteles (2000) elabora a ética como filosofia prática do "agir bem" e em busca da

4 A Extensible Markup Language (XML) é uma linguagem de marcação recomendada pela W3C para a criação de documentos com dados organizados hierarquicamente, tais como textos, banco de dados ou desenhos vetoriais. A linguagem XML é classificada como extensível porque permite definir os elementos de marcação. 
perfeição, englobando o social e o político, em oposição à filosofia teórica. A partir desse preceito seria possível alcançar as virtudes intelectuais (dianoéticas) e as virtudes morais (éticas). As virtudes dianoéticas dependem da instrução (experiência e tempo); já as virtudes éticas dependem do hábito e são disposições de nossas emoções que nos ajudam a responder corretamente a situações práticas (hábito). No campo profissional (deontológico), a conduta ética também enseja um caráter íntegro. Então, a "Integridade é o que se espera de todo cientista em sua vida acadêmica. [...] A ciência é patrimônio universal, tem espírito coletivo e sua construção exige integridade e compromisso com a verdade, mas está sujeita a erros como qualquer atividade humana” (Pinto, 2015: 297).

O vocábulo 'integritate' (Integridade) é um substantivo feminino oriundo do latim e significa a qualidade do que é íntegro, completo, inteireza, retidão. Também é considerado sinônimo de boa conduta, honestidade e imparcialidade. Outrossim, não é por acaso que "A confiança é o pilar da atividade de pesquisa” (Academia Brasileira de Ciências, 2013: 3). A fim de auxiliar os pesquisadores, a Academia Brasileira de Ciências publicou, em seu guia, oito princípios éticos relacionados à integridade científica, e alguns deles diretamente ligados à autoria. São eles:

(i) Honestidade na apresentação, execução e descrição de métodos e procedimentos da pesquisa e na interpretação dos resultados; (ii) Confiabilidade na execução da pesquisa e na comunicação de suas conclusões; (iii) Objetividade na coleta e no tratamento de dados e informações, na apresentação de provas e evidências e na interpretação de resultados; (iv) Imparcialidade na execução da pesquisa, na comunicação e no julgamento das contribuições de outros; (v) Cuidado na coleta, armazenamento e tratamento de dados e informações; (vi) Respeito por participantes e objetos do trabalho de pesquisa, sejam seres humanos, animais, o meio ambiente ou objetos culturais; (vii) Veracidade na atribuição dos créditos a trabalhos de outros; (viii) Responsabilidade na formação e na supervisão do trabalho de jovens cientistas. (Academia Brasileira de Ciências, 2013: 6)

Outros exemplos são a Declaração de Singapura sobre Integridade em Pesquisa em 2010 e a Declaração de Montreal sobre Integridade na Pesquisa Colaborativa Transfronteiriça em 2013. Essas declarações corroboram os discursos e as visões presentes na literatura científica sobre a integridade da pesquisa e o fato de ser a ciência considerada como algo universal e que não está limitada à área, disciplina e localização geográfica. Ambas as declarações reforçam os princípios e as responsabilidades relevantes para a colaboração entre parceiros individuais e institucionais que contribuam para o avanço da ciência, reiterando, ainda, que são fundamentais para a integridade da 
investigação colaborativa. A maioria dos itens descritos nessas declarações tem forte ligação com a autoria, coautoria e colaboradores.

O COPE também alerta para o fato de que devem criadas políticas claras sobre a autoria, de forma que permitam serem identificadas as contribuições de cada autor, que visem à transparência, além de os autores estarem em posição de atender aos requisitos de autoria e contribuição, bem como os processos para gerenciar possíveis disputas.

O COPE cita algumas definições sobre autoria em seus documentos, inclusive a estabelecida pelo Council Science Editors (CSE). ${ }^{6}$ Com a finalidade de orientar editores e autores, esta entidade possui inúmeras definições e situações expostas em seu site e em publicações oficiais, traduzidas e publicadas no Brasil pela Associação Brasileira de Editores Científicos (ABEC). ${ }^{7}$

Todavia, apesar da variedade de orientações disponíveis para os autores, editores e instituições, são diversos os matizes de abusos cometidos em autoria e que devem ser combatidos. É comum a inclusão do nome de professores orientadores ou coorientadores que efetivamente contribuíram com o desenvolvimento da escrita científica; no entanto, tendo em vista as questões éticas, as contribuições de cada uma das partes devem ser discutidas antes da determinação da ordem de autoria e da inclusão dos nomes. Por outro lado, coordenadores, chefes, diretores e afins, mesmo sem terem contribuído com a produção do artigo, podem vir a exigir a inclusão de seus nomes em trabalhos de caráter científico, fato que, para Montenegro e Alves (1987), trata-se de um comportamento reprovável, muitas vezes imposto por chefes que desejam ser agradados ou que usam o seu nome e prestígio sob o argumento de valorizar o trabalho.

Assim, "[...] há chefes que fazem questão de que seu nome seja incluído em todos os trabalhos de seu grupo. Não é necessário enfatizar o absurdo desta posição que por si define um baixo nível ético que certamente se reflete na seriedade com que o trabalho foi realizado e até põe em dúvida seus resultados" (Montenegro e Alves, 1987: 191-192). Da mesma maneira, o Conselho Nacional de Desenvolvimento Científico e Tecnológico - CNPq (2013) instituiu diretrizes $^{8}$ sobre conduta ética na pesquisa que envolve a questão da autoria.

5 O COPE possui uma vasta gama de fluxogramas e diretrizes norteadoras para pesquisadores e editores de periódicos a fim de incentivar as melhores práticas relacionadas à produção de conhecimento em publicações científicas (Authorship and Contributorship): https://publicationethics.org/authorship

6 White Paper on Publication Ethics: https://www.councilscienceeditors.org/resource-library/ editorial-policies/white-paper-on-publication-ethics/

7 Diretrizes do CSE para Promover Integridade em Publicações de Periódicos Científicos: https://www.abecbrasil.org.br/arquivos/whitepaper_CSE.pdf

8 Diretrizes básicas para a integridade na atividade científica (CNPq): http://memoria.cnpq.br/ diretrizes 
O plágio consentido, modalidade em que há a formação de conluio e a inclusão do nome do amigo ou colega como coautor, também é bastante corriqueiro e costuma funcionar como uma troca de favores. Essa prática favorece o acréscimo de produções no currículo desses profissionais a fim de obter vantagens, mesmo sem ter o conhecimento pleno sobre o assunto abordado no manuscrito. Esse tipo de conduta coloca em dúvida a integridade da pesquisa e, ao mesmo tempo, pode denegrir todo o histórico de produções e reputação do pesquisador.

Não estabelecer as autorias de um trabalho antes de seu início ou durante sua produção pode tornar-se desagradável futuramente no momento de tomar a decisão da ordem dos nomes dos autores. Volpato (2016: 107) alerta que seja estabelecida a autoria do trabalho durante a sua concepção; ademais, exclusões podem ocorrer a qualquer momento, a fim de que não ocorra o desvio de autoria.

Se o autor é quem escreve e contribuiu substancialmente, então, o mais coerente é a ordem de autoria baseada na contribuição de cada um. Dessa forma, quem mais contribuiu será o primeiro autor, independentemente de orientação técnica, cargo, posição hierárquica ou afins. Ressaltamos que se deve analisar e respeitar as especificidades de cada área com relação a esse quesito.

Há casos em que a autoria é atribuída para quem coletou os dados, fez a análise estatística, emprestou material e financiou a pesquisa. De acordo com Volpato (2016: 108), "Coletar dados, emprestar material e financiar a pesquisa não é suficiente para ser autor do texto. [...] A análise estatística fornece conclusões, [...] mas são ainda conclusões rudimentares, que apenas mostram igualdades ou diferenças entre valores, ou então correlações”. Destarte, a análise estatística como critério de autoria deve ser analisada cautelosamente, observando as normativas de cada área, uma vez que Volpato (2016: 108) esclarece: "[...] a lista de autorias não pode ser resumida a uma lista de itens de participação”.

Ainda de acordo com o autor supracitado, inserir na lista de autores pessoas que deram sugestões é outro equívoco comum e reforça que "[...] dar sugestões não significa ser dono!”. (Volpato, 2016: 112), esclarecendo, ainda, que não devem ser incluídas colaborações pontuais de autoria.

Por sua vez, Pereira (2011: 164) enfatiza que os agradecimentos "Ficarão restritos às pessoas (e também instituições) que contribuíram de maneira relevante para o trabalho, mas cujo auxílio não foi tão essencial que justifique a inclusão de seus nomes na coautoria do artigo".

Em contraste com os argumentos de Volpato (2016), os agradecimentos são importantes porque indicam informações sobre as redes informais de colaboração e avaliadores confiáveis (Mullins e Mullins, 1973), além disso, revelam as 
participações efetivas realizadas nas pesquisas e que são invisíveis. Embora os agradecimentos não sejam considerados contribuições substanciais que assegurem autoria, ainda assim são fundamentais para a acumulação do capital social na ciência moderna (Bourdieu, 1975; Cronin, 2005; Paul-Hus et al., 2017). Nesse sentido, os estudos de McCain (1991) e Cronin et al. (1993) sugeriram em suas taxonomias as seguintes classificações para os agradecimentos: suporte conceitual e cognitivo; financeiro; acesso a dados e materiais; assistência técnica; e preparação de manuscritos. Outros autores distinguem essas funções em: suporte técnico; coleta de dados; processamento de dados; operação de máquinas de laboratório; elaboração de análises estatísticas; suporte teórico, edição e comentários (Patel, 1973; Heffner, 1981).

A colaboração na ciência e a coautoria permitem que os pesquisadores compartilhem conhecimentos, dividam tarefas e resolvam problemas de pesquisa em comum, ademais, o crescimento das taxas bibliométricas correspondentes à coautoria ao longo das últimas décadas é uma prova desse reflexo no campo científico (Bordons e Gómez, 2000; Díaz-Faes e Bordons, 2014).

O primeiro estudo sobre a colaboração relacionada aos agradecimentos foi realizado por Crawpord e Biderman (1970), no qual os autores analisaram notas de rodapé e outros elementos paratextuais a fim de identificar os agradecimentos relacionados às pesquisas, à colaboração, infraestrutura e financiamento. De acordo com Paul-Hus et al. (2017), as análises dos referidos autores não tiveram o reconhecimento esperado, entretanto, esse cenário mudou em 2008 quando a base de dados Web of Science (WoS) iniciou a indexação das informações que constavam nos agradecimentos dos artigos científicos. A partir disso, a WoS levantou uma série de informações relevantes sobre as fontes de financiamento, as relações entre o financiamento, produtividade e o impacto das publicações.

Para Desrochers et al. (2018), os agradecimentos podem ser motivados por razões diversas, como o reconhecimento pelo apoio prestado por outras pessoas, instituições e financiadores. Para os autores, os agradecimentos são difíceis de interpretar e avaliar formalmente em pesquisas por conta de sua relação ambígua e falta de padronização, a começar por sua natureza e em diferentes estilos e formatos (seção final, parágrafo final, nota de rodapé ou corpo do texto). Consequentemente, inúmeros autores apontaram a necessidade de estabelecer normas, diretrizes e políticas claras sobre os agradecimentos, bem como sugerir quais os formatos em que deve se apresentar e quais são os critérios de inclusão (Brown, 2009; Chubin, 1975; Desrochers et al., 2018; McCain, 1991; Pontille, 2001, 2004; Rong, Grant e Ward, 1989).

Há diversos fatores associados à autoria e à produção científica, tais como enorme valorização da quantidade versus a qualidade. A cultura do Publish 
or Perish ("Publique ou Pereça") está diretamente ligada ao crescimento do número de periódicos - alguns predatórios -; à criação de coletâneas de artigos publicados em número especial ou temático, suplementos, geralmente avaliados pelos próprios organizadores e que também são os mesmos responsáveis pela publicação ou seu financiamento; e, ainda, à proliferação de formas questionáveis de autoria e publicações indevidas (Pereira, 2011).

O editor da Harvard University Press publicou em seu livro a seguinte crítica sobre a valorização da quantidade de artigos em detrimento da qualidade:

Os órgãos de avaliação perguntam quanto um autor publica, mas não se debruçam sobre o que chega aos leitores. Enfatiza-se a produtividade, não a recepção. Assim, vive-se um momento em que a publicação de trabalhos com pouco ou nenhum sentido aumenta, enquanto o profissional que reluta em publicar, esperando o momento certo ou chegar a textos significativos, tende a ser cada vez mais ignorado - e até marginalizado. (Waters, 2006 citado por Pereira, 2011: 162)

O CSE (2018) cita ainda outros tipos de autoria que podem desencadear casos indevidos:

- Anônima: Sem a revelação do nome do autor de forma transparente para requerer a sua responsabilidade pública, não sendo possível para o editor científico publicar o manuscrito. A publicação de estudos, relatórios ou documentos de outra natureza usando pseudônimos ou anonimamente não é permitido na ciência, exceto em casos extremamente raros, quando o autor alegar sérias dificuldades (ameaça à segurança pessoal ou perda de emprego);

- Autoria de Grupo: É aplicada quando um grupo de pesquisadores colaborou em um projeto em comum. Pela imprecisão em listar todos os colaboradores, pois, alguns não talvez não atendam aos critérios básicos de autoria do ICMJE ou o número de autores pode ser limitado por alguns publicadores, os autores precisam pensar definir quem será creditado como autor principal e responsável pelo conteúdo;

- Autores falecidos ou incapacitados: Nos casos em que um autor morre ou está incapacitado durante o processo de redação, apresentação ou revisão por pares, os coautores devem obter a documentação de autorização dos direitos autorais ou uma procuração familiar legal para a divulgação da pesquisa.

Outros exemplos de má conduta em publicações relacionados à autoria são: artigos oriundos de fabricação de dados, falsificação, plágio e roubo de ideias 
(vampirismo intelectual); plágio; publicações repetidas (autoplágio); fragmentação exagerada dos resultados da pesquisa (the least publishable unit ou salami science); autoria presenteada; autor fantasma (Ghost author ou Ghost writer).

Existe, ainda, outro tipo de má conduta relacionada à autoria: a utilização de sites ou softwares que geram artigos automaticamente, sem nenhum critério e rigor científico: SciGen (https://pdos.csail.mit.edu/archive/scigen/). O SciGen foi desenvolvido por três estudantes do Massachusetts Institute of Technology (MIT): Dan Aguayo, Jeremy Stribling e Max Krohn. Todavia, apesar de ser uma ferramenta que cria artigos falsos, a intenção não era fraudar e nem cometer qualquer tipo de má conduta, aliás, o SciGen foi criado com o propósito de expor a baixa qualidade de muitos periódicos - especialmente os predatórios - e de seus revisores, além de outras conferências profissionais que aceitaram manuscritos inferiores, a exemplo de artigos publicados pela Springer e pelo Institute of Electrical and Electronic Engineers (IEEE), que retiraram de circulação mais de 120 artigos falsos (Noorden, 2014). Semelhante ao SciGen, temos: O Mathgen (http://thatsmathematics. com/mathgen/), criado a partir do código-fonte do SciGen.

Para combater esse tipo de fabricação de artigo e detectar se foi construído de forma automática, existe o SciGen Detect (http://scigendetection. imag.fr/main.php), também conhecido como Anti SciGen), desenvolvido pelo pesquisador Cyril Labbé, do Laboratoire d'Informatique de Grenoble. Há, ainda, o Automatic SBIR Proposal Generator (http://www.nadovich.com/ chris/randprop/), um gerador de propostas de financiamento.

Outras ferramentas online duvidosas disponíveis em opções pagas e gratuitas são os Spinners para produção de textos: também conhecidos como geradores de texto automático, permitem a criação de versões únicas de um texto já publicado, substituindo algumas palavras por sinônimos e reordenando frases e parágrafos inteiros tais como o Word Spinner (http://spinner. com.br/), Turbine Text (https://www.turbinetext.com), Spinner Português (https://spinnerportugues.com/), Invertexto (https://www.invertexto.com/), Copywriter Lab (http://copywriterlab.com/spinner-artigo/), entre muitos outros, e até mesmo o verificador de plágio online Plagiarisma (http://plagiarisma.net/spinner.php) tem um módulo Spinner para reescrita de textos, o que, para algumas pessoas, pode ser um tanto contraditório para um verificador de plágio.

Outros exemplos de uso da tecnologia para gerar manuscritos escritos por máquinas e que não foram considerados fraude: no ramo literário, em 2016, Hitoshi Matsubara criou um livro a partir de inteligência artificial (AI) e aprendizagem de máquina (machine learning) e quase ganhou um prêmio de literatura no Japão.?

9 Notícia sobre o livro de Hitoshi Matsubara: https://bigthink.com/natalie-shoemaker/a-japanese-ai-wrote-a-novel-almost-wins-literary-award. 
Em 2017, o programador Zack Thoutt alimentou redes neurais com os conteúdos dos livros já publicados da saga Game of Thrones ${ }^{10}$ de George R. R. Martin e usou um algoritmo para escrever os capítulos finais ainda não escritos pelo autor.

No mesmo ano, o laboratório de mídia do MIT, na figura dos pós-doutores Pinar Yanardag e Manuel Cebrian, e do Professor Iyad Rahwan, desenvolveram a Shelley (http://shelley.ai/): com a inteligência artificial, aprendeu toda a estrutura literária para escrever contos de terror no Twitter (https:// twitter.com/shelley_ai). Por meio da hashtag \#youturn, usuários do microblog enviavam mensagens e Shelley continuava a sequência narrativa dos contos a partir dali.

O último exemplo é o algoritmo Beta Writer, desenvolvido para criar um livro científico. Com a utilização de algoritmos, da inteligência artificial e das redes neurais, a editora Springer Nature publicou o seu primeiro livro totalmente sem autores humanos, escrito por máquina, intitulado Litbium-Ion Batteries. ${ }^{11}$ A iniciativa da editora contou com a parceria da Universidade de Frankfurt e usou o algoritmo Beta Writer. O algoritmo organizou todas as pesquisas publicadas sobre baterias de lítio nos últimos três anos, criou resumos de cada um e os conectou ao conteúdo, inclusive, gerando índice, citações e referências automaticamente. Em um mundo cada vez mais dominado por máquinas, esses casos não foram considerados como má conduta ou fraude, entretanto, é bastante questionável a criação de um conteúdo completamente automatizado, mesmo que tenha sido programado para seguir certas normas e padrões estabelecidos, como citar e referenciar, isto é, dar os devidos créditos aos autores.

Até mesmo a autoria, a comunicação científica e a ciência têm sido afetadas pela artificialidade e a desintegração de práticas, costumes e estilos de vida, situando-se na lógica da modernidade líquida (Bauman, 2001), onde a volatilidade da 'tecnologia líquida' passou a ser um bem tecnológico com valor social significativo maior do que a produção de conhecimento. Assim, a construção do saber e de uma ciência sólida e transparente depende da boa conduta dos pesquisadores e da busca pela integridade, um comportamento ideal e diferente de alguns exemplos apresentados nesta seção.

10 Os capítulos gerados no projeto de Zack Thoutt estão disponíveis no GitHub: https://github. com/zackthoutt/got-book-6/tree/master/generated-book-v1. Ver também: https://super.abril. com.br/cultura/inteligencia-artificial-esta-escrevendo-o-fim-de-game-of-thrones/.

11 O livro está disponível para download: https://link.springer.com/book/10.1007/978-3-030-16800-1. Ver também: https:/www.startse.com/noticia/nova-economia/63337/livro-inteligencia-artificial?fbclid=IwAR1MQ1YOt-7afJUL5qOG7I_bxqZmKX0gYCuOBQv3sNY7ijhmh7lfXQMFfDM. 


\section{Considerações Finais}

Diante do exposto, acreditamos que a autoria é o próprio ato de produzir algo, inventar, criar, fazer nascer, moldar, seja de maneira escrita ou em outras formas de expressão. A contribuição e colaboração, dependendo do grau e medida, poderá adquirir o status de autoria ou coautoria, desde que seja avaliada, baseada em critérios éticos estabelecidos, de acordo com cada área e suas particularidades.

Reiteramos os conceitos de autor, autoria, coautor e colaborador apresentados nesta comunicação em perspectivas diferentes, algumas semelhantes, porém, sem uma definição fechada e que englobe todo o conjunto dessas condições, ou, na visão foucaultiana, a função 'autor'. Ainda assim, pode-se pensar em um papel binário e tradicional para o autor, tendo em vista diversos exemplos e casos de autoria apresentados neste manuscrito, nos quais, em alguns, sequer a autoria existe da maneira tradicional, e em outros a autoria foi suplantada pela tecnologia.

Não foi objeto estudado aqui a autoria em obras audiovisuais e fílmicas, entretanto, refletimos sobre os papéis envolvidos nessas produções e concluímos que é bastante simplista atribuir autoria única em obras dessa natureza, visando à gama de papéis envolvidos nessas produções, tais como o diretor, produtor, redator, atores etc. A própria área do Cinema ainda não tem um conceito definido de autoria, então, utiliza-se do recurso de informações dos créditos ao final dos filmes, onde são listados todos os papéis e funções desempenhadas por todos os envolvidos no projeto.

A determinação da figura do autor principal, bem como o estabelecimento da ordem de autoria desde o início, a fim de evitar conflitos, são questões antigas na ciência. Nesse sentido, concorda-se que a atribuição, a definição do nível de contribuição e o papel desempenhado possam ser resolvidos com o uso de taxonomias, na finalidade de dirimir eventuais problemas relacionados à autoria, a exemplo da CRediT, e com a associação da padronização e uso de citações interoperáveis e indexadas.

Os pesquisadores podem criar um conjunto de diretrizes para definir suas contribuições e tarefas, ou podem optar pela adoção de modelos ou políticas de autoria sugeridos por sua área, instituição e pelos periódicos científicos, considerando, ainda, a taxonomia como o modelo CRediT. Se todos contribuíram igualmente, os autores devem buscar formas de sinalizar isso em suas declarações de autoria e nos manuscritos produzidos, por meio de uma nota, por exemplo, desde que seja permitida pela publicação ou instituição.

Também evidenciou-se, ao longo deste texto, que os critérios do ICMJE são bastante difundidos e aceitos, entretanto, ainda são insuficientes para 
reconhecer todos os esforços envolvidos na pesquisa acadêmica, a exemplo de autoria de conjuntos de dados [datasets] em que há o autor da pesquisa, mas este contou com a ajuda de outros colaboradores para a coleta, preparação, processamento, documentação, entre outras etapas com vistas a preservar os dados e compartilhá-los em repositórios apropriados, sendo um dos objetivos o envio para uma revista juntamente com o seu artigo ou simplesmente divulgá-los entre os seus pares.

Um aspecto relevante evidenciado na literatura científica é a afirmativa de que devem ser listados na seção de agradecimentos aqueles que não atendem aos critérios de autoria. Vale ressaltar que, em algumas áreas, o último autor representa a figura do orientador ou o líder de um grupo. Inclusive, ser o último autor, nessas áreas, demonstra que, além de o orientador estar exercendo a função de coautor, também está contribuindo para a formação de mais recursos humanos em sua área de atuação. Por isso, recomenda-se a constante revisão e verificação frequente das definições de autor, coautor, colaborador, da ordem de autoria e dos critérios de contribuição, afinal, mudanças nas funções e nas responsabilidades podem ocorrer.

Para administrar todas as mudanças, sugestões e alterações em manuscritos com vários autores, é necessário estabelecer uma estratégia de escrita para que as escolhas feitas tenham impacto no resultado do trabalho. Para isso, sugere-se a adoção de tecnologias de trabalho colaborativas, a exemplo das mais simples, como o Google Docs, Overleaf, Microsoft Office online, Libre Office online, entre tantas outras opções disponíveis no mercado, até à tecnologia Blockchain: trata-se de um protocolo de confiança que tem como principais objetivos a auditoria e a descentralização como medida de segurança das informações e dos dados. Trata-se da mesma tecnologia usada em criptomoedas, como o Bitcoin. Assim, a contribuição de cada autor, coautor e colaborador fica registrada, é constantemente auditada e validada, facilitando a determinação dos créditos e ordem de autoria futuramente.

Ademais, a Blockchain permite avaliar aspectos críticos concernentes à comunicação científica e atribuir os devidos créditos autorais e de propriedade intelectual a cada autor. Diversos projetos voltados para essa tecnologia surgiram nos últimos anos, a fim de mitigar alguns problemas enfrentados na atualidade, por exemplo, a abertura da pesquisa científica, ética, segurança, transparência, acesso às informações científicas, auditoria, os custos envolvidos nas publicações científicas e revisão por pares.

O estabelecimento de cronogramas e listas de tarefas distribuídas entre o grupo de autores é uma estratégia interessante para acompanhar as atividades de cada autor, suas atribuições e trabalhar de acordo com uma meta e prazo para a finalização da tarefa, visando submeter o manuscrito para avaliação e publicação. 
Por fim, esclarecemos que não existe uma abordagem correta, única e capaz de resolver os problemas de autoria, todavia, o estabelecimento de processos, práticas, estruturação e organização de um grupo de autores que visam à produção de um manuscrito promove soluções, boas práticas e auxilia na resolução de problemas em torno da autoria. Além disso, a adoção dessas práticas gera confiança, promove a abertura e transparência entre os pares.

Agradecimentos

Agradecemos aos avaliadores pelas valorosas contribuições, sugestões e críticas que foram essenciais para ampliar o escopo deste artigo. Agradecimentos especiais ao Programa de Pós-Graduação em Ciência da Informação da Universidade Federal do Ceará (PPGCI-UFC) e a todos os professores pela acolhida, apoio e oportunidade.

\section{REFERENCIAS}

Academia Brasileira de Ciências. 2013. Rigor e integridade na condução da pesquisa científica - Guia de recomendações de práticas responsáveis. Rio de Janeiro: ABC. Acesso em: 1 set. 2016. http://www.abc.org.br/IMG/pdf/doc-4311.pdf

Acosta-Hoyos, Luís Eduardo. 1980. Colégios invisiveis: uma nova alternativa para o problema de informação técnico-científica, Brasília: Embrapa, Departamento de Informação e Documentação.

Alves-Mazzotti, Alda Judith. 2002. "O método nas ciências sociais”, em O método nas ciências naturais e sociais: pesquisa quantitativa e qualitativa, editado por Alda Judith Alves-Mazzotti, 109-187. São Paulo: Pioneira Thomson Learning.

Aristóteles. 2000. Ética a Nicômaco. São Paulo: Martin Claret.

Bakhtin, Mikhail. 2011. Estética da criação verbal. São Paulo: Martins Fontes.

Barthes, Roland. 1988. "A morte do autor", em O rumor da língua, 65-70. São Paulo: Brasiliense.

Bauman, Zygmunt. 2001. Modernidade líquida, Rio de Janeiro: Zahar.

Bernal, John Desmond. 1939. The Social function of Science, London: George Routledge \& Sons. Acesso em: 03 dez. 2018.

https://ia801606.us.archive.org/22/items/in.ernet.dli.2015.188098/2015.188098. The-Social-Function-Of-Science.pdf

Biagioli, Mario. 2003. Scientific authorship: credit and intellectual property in science. New York: Routledge.

Bianchetti, Lucídio, Antônio Zuin e Obdália Ferraz. 2018. Publique, apareça ou pereça: produtivismo acadêmico, pesquisa administrativa e plágio nos tempos da cultura digital, Salvador: Edufba. 
Bordons, María e Isabel Gómez. 2000. "Collaboration networks in Science", em The Web of Knowledge: A Festschrift in Honor of Eugene Garfield, 197-213. Medford, NJ: Information Today, Inc. \& ASIS.

Bourdieu, Pierre. 1975. "The specificity of the scientific field and the social conditions of the progress of reason". Social Science Information 14 (6): 19-47.

Bourdieu, Pierre. 2001. Science de la science et réflexivité. Paris: Éditions Raisons d'agir.

Brown, Robert. 2009. "How scholars credit editors in their acknowledgements". Journal of Scholarly Publishing 40 (4): 384-398.

Certeau, Michel de. 2014. A invenção do cotidiano: 1. Artes de fazer, 22ª ed. Petrópolis: Vozes.

Cervo, Amado e Pedro Bervian. 2002. Metodologia científica, $5^{a}$ ed. São Paulo: Prentice Hall.

Chartier, Roger. 2009. A aventura do livro: do leitor ao navegador. São Paulo: Unesp.

Chartier, Roger. 2012. Autoria e história cultural da ciência. Rio de Janeiro: Azougue.

Christofoletti, Rogério. 2006. "Ética e autoria: notas preocupadas sobre a pesquisa científica contemporânea”. Vozes e diálogos (Itajaí) 8 (8): 57-65. Acesso em: 03 dez. 2018. https://siaiap32.univali.br//seer/index.php/vd/issue/viewIssue/252/18

Chubin, Daryl E. 1975. "Trusted assessorship in science: A relation in need of data". Social Studies of Science, 5 (3): 362-367.

COPE (Committee on Publication Ethics). 2014. What constitutes authorship? COPE Discussion Document. Acesso em: 03 dez. 2018.

https://publicationethics.org/files/u7141/Authorship_DiscussionDocument_0_0.pdf

COPE. 2018. Authorship and contributorship. Acesso em: 03 dez. 2018. https://publicationethics.org/authorship.

Costas, Rodrigo y María Bordons. 2011. "Do age and professional rank influence the order of authorship in scientific publications? Some evidence from a micro-level perspective". Scientometrics 88 (1): 145161.

Crane, Diana. 1988. Invisible colleges: diffusion of knowledge in scientific communities, Chicago: The University of Chicago Press.

Crawpord, Elisabeth T. y Albert D. Biderman. 1970. "Paper money: Trends of research sponsorship in American sociology journals". Social Science Information 9 (1): $50-77$. http://doi.org/10.1177/053901847000900103

Cronenwett, Jack L. y James M. Seeger. 2005. "Criteria for authorship”. Journal of Vascular Surgery 42: 599. Acesso em: 10 abr. 2019. https://core.ac.uk/download/ pdf/82649913.pdf

Cronin, Blaise. 2005. The Hand of Science: Academic Writing and its Rewards. Lanham, Maryland: Scarecrow Press.

Cronin, Blaise. 2001. "Hyperauthorship: A postmodern perversion or evidence of a structural shift in scholarly communication practices?". Journal of the American Society for Information Science and Technology 52 (7): 558-569.

Cronin, Blaise. 2015. "The writing on the wall". Journal of the Association for Information Science and Technology 66 (5): 873-875.

Cronin, Blaise, Gail McKenzie, Lourdes Rubio y Sherrill Weaver-Wozniak. 1993. "Accounting for influence: Acknowledgments in contemporary sociology". Journal of the American Society for Information Science 44 (7): 406-412. 
CSE (Council Science Editors). 2018. CSE's White Paper on Promoting Integrity in Scientific Journal Publications. Acesso em: 03 dez. 2018. https://www.councilscienceeditors.org/wp-content/uploads/CSE-White-Paper_2018-update-050618.pdf

Desrochers, Nadine, Adèle Paul-Hus, Stefanie Haustein, Rodrigo Costas, Philippe Mongeon, Anabel Quan-Haase, Timothy D. Bowman, Jen Pecoskie, Andrew Tsou y Vincent Larivière. 2018. "Authorship, citations, acknowledgments and visibility in social media: Symbolic capital in the multifaceted reward system of Science". Social Science Information 57 (2): 223-248. http://doi.org/10.1177/0539018417752089

Díaz-Faes, Adrián A. y María Bordons. 2014. "Acknowledgments in scientific publications: Presence in Spanish science and text patterns across disciplines". Journal of the Association for Information Science and Technology 65 (9): 1834-1849.

Elias, Claudia de Souza Rodrigues, Leandro Andrade da Silva, Mirian Teresa de Sá Leitão Martins, Neide Ana Pereira Ramos, Maria das Graças Gazel de Souza y Rodrigo Leite Hipólito. 2012. "Quando chega o fim? Uma revisão narrativa sobre terminalidade do período escolar para alunos deficientes mentais". SMAD: Revista Electrónica en Salud Mental, Alcohol y Drogas 8 (1): 48-53. Acesso em: 03 dez. 2018. http://www.revistas.usp.br/smad/article/view/49594

Foucault, Michel. 1992. O que é um autor? Lisboa: Vega.

Foucault, Michel. 2005. A ordem do discurso. São Paulo: Loyola.

Garvey, William D. 1979. Communication: the essence of science: facilitating information among librarians scientists, engineers and students. Oxford: Pergamon Press.

Heffner, Alan G. 1981. "Funded research, multiple authorship, and subauthorship collaboration in four disciplines". Scientometrics 3 (1): 5-12.

Hilário, Carla Mara, Maria Cláudia Cabrini Grácio y José Augusto Chaves Guimarães. 2018. "Aspectos éticos da coautoria em publicações científicas". Em Questão (Porto Alegre) 24 (2): 12-36. Acesso em: 10 out. 2018.

https://seer.ufrgs.br/EmQuestao/article/view/76312

ICMJE (International Committee of Medical Journal Editors). 2019. Recommendations for the conduct, reporting, editing, and publication of scholarly work. Acesso em: 1 set. 2016. https://goo.gl/rBnpS2

Krokoscz, Marcelo. 2015. Outras palavras sobre autoria e plágio. São Paulo: Atlas.

Lacan, Jacques. 1985. O seminário: livro 20 - Mais, ainda. Rio de Janeiro: Zahar.

Larivière, Vincent, Nadine Desrochers, , Benoît Macaluso, Philippe Mongeon, Adèle Paul-Hus y Cassidy R. Sugimoto. 2016. "Contributorship and division of labor in knowledge production". Social Studies of Science 46 (3): 417-435. http://doi.org/10.1177/0306312716650046

Lunsford, Andrea y Lisa Ede. 1990. Singular Texts/Plural Authors: Perspectives on Collaborative Writing. Illinois: Board of Trustees Southern Illinois University.

McCain, Katherine. W. 1991. "Communication, competition, and secrecy: The production and dissemination of research related information in Genetics". Science, Technology \& Human Values 16 (4): 491-516.

http://doi.org/10.1177/016224399101600404

Mauss, Marcel. 2003. "Ensaio sobre a dádiva”, em Sociologia e antropologia, 183-314. São Paulo: Cosac Naify. 
Meadows, Arthur Jack. 1999. A comunicação científica. Brasília: Briquet de Lemos.

Merton, Robert King. 1977. Sociology of science: theoretical and empirical investigations. Chicago: University of Chicago Press.

Merton, Robert King. 1993. On the shoulders of giants: a Shandean postscript. Chicago: University of Chicago Press.

Monteiro, Rosangela, Fabio Biscegli Jatene, Saul Goldenberg, Dinah Aguiar Población y Rosely de Fátima Pellizzon. 2004. "Critérios de autoria em trabalhos científicos: um assunto polêmico e delicado". Revista Brasileira de Cirurgia Cardiovascular (São José do Rio Preto) 19 (4): III-VIII. Acesso em: 03 dez. 2018. http://www.scielo.br/scielo.php?script=sci_arttext\&pid=S0102-76382004000400002

Montenegro, Mario y Venâncio Ferreira Alves. 1987. "Critérios de autoria e co-autoria em trabalhos científicos". Revista do Instituto de Medicina Tropical de São Paulo (São Paulo) 29 (4): 191-193. Acesso em: 27 mar. 2016. https://goo.gl/SIgqQQ

Mueller, Suzana Pinheiro Machado. 1994. "O impacto das tecnologias de informação na geração do artigo científico: tópicos para estudo". Ciência da Informação (Brasília) 23 (3): 309-317. Acesso em: 03 dez. 2018. http://revista.ibict.br/ciinf/article/view/528/528

Mullins, Nicholas. C. y Carolyn J. Mullins. 1973. Theories and Theory Groups in Contemporary American Sociology. New York: Harper and Row.

Noorden, Richard Van. 2014. "Publishers withdraw more than 120 gibberish papers". Nature. http://doi.org/10.1038/nature.2014.14763

Office Research of Integrity. 2019. Authorship. Acesso em: 10 abr. 2019. https://ori.hhs.gov/Chapter-9-Authorship-and-Publication-authorship

Oliveira, Eloísa da Conceição Príncipe de. 2009. "Percursos digitais da comunicação científica”, em Desafios do impresso ao digital: questões contemporâneas de informação e conbecimento, organizado por Gilda Maria Braga e Lena Vania Ribeiro Pinheiro, 289-312. Brasília: Ibict.

Orlandi, Eni Pulcinelli. 2004. Interpretação: autoria, leitura e efeitos do trabalho simbólico. Campinas: Pontes.

Patel, Narsi. 1973. "Collaboration in the professional growth of American sociology”. Social Science Information 12: 77-92.

Paul-Hus, Adèle, Philippe Mongeon, Maxime Sainte-Marie y Vincent Larivière. 2017. "The sum of it all: Revealing collaboration patterns by combining authorship and acknowledgments”. Journal of Informetrics 11 (1): 80-87. http://doi.org/10.1016/j.joi.2016.11.005

Pereira, Maurício Gomes. 2011. Artigos cientificos: como redigir, publicar e avaliar. São Paulo: Guanabara Koogan.

Petroianu, Andy. 2010. "Critérios de autoria e avaliação de uma publicação científica”. Revista de Psiquiatria Clínica (São Paulo) 37 (1): 1-5. Acesso em: 10 out. 2018. http://www.scielo.br/pdf/rpc/v37n1/a01v37n1

Pinto, Angelo C. 2015. "Integridade científica: compromisso da SBQ". Química Nova (São Paulo) 38 (3): 297. Acesso em: 15 out. 2017. http://doi.org/10.5935/0100-4042.20150044

Pontille, David. 2001. "L'auteur scientifique en question: pratiques en psychologie et en sciences biomédicales”. Social Science Information 40 (3): 433-453. 
Pontille, David. 2004. La signature scientifique. Paris: Editions du CNRS. Acesso em: 10 abr. 2019. https://www.persee.fr/doc/arss_0335-5322_2002_num_141_1_2822

Rennie, Drummond, Veronica Yank y Linda Emmanuel. 1997. "When authorship fails: a proposal to make contributors accountable". JAMA 278: 579-585. doi: 10.1001/jama.1997.03550070071041

Rong, Xue Lan, Linda Grant y Kathryn B. Ward. 1989. "Productivity of women scholars and gender researchers: Is funding a factor?" The American Sociologist 20 (1): 95-100.

Snow, Charles Percy. 1956. The two cultures. Cambridge: Cambridge University Press.

Suber, Peter. 2007. "Creating an intellectual commons through open access", em Understanding knowledge as a commons: from theory to practice, editado por Charlotte Hess e Elinor Ostrom, 171-208. Cambridge: MIT Press. Acesso em: 03 dez. 2018. http://www.wtf.tw/ref/hess_ostrom_2007.pdf

Targino, Maria das Graças. 2010. “Orientador ou tutor é autor?”. Informação E Informação 15 (1): 145-156. doi: 10.5433/1981-8920.2010v15n1espp145

Valls, A. 2008. O que é ética, 9a ed. São Paulo: Brasiliense.

Volpato, Gilson. 2016. Dicas para redação científica, $4^{a}$ ed. revista e ampliada. Botucatu, SP: Best Writing.

Waltman, Ludo. 2012. "An empirical analysis of the use of alphabetical authorship in scientific publishing". Journal of Informetrics 6 (4): 700-711. https://doi.org/10.1016/j.joi.2012.07.008

World Conferences On Research Integrity. 2010. Declaração de Singapura sobre Integridade em Pesquisa. Acesso em: 03 dez. 2018. https://wcrif.org/documents/303-ss-portuguese/file

World Conferences On Research Integrity. 2013. "Declaração de Montreal sobre Integridade na Pesquisa Colaborativa Transfronteiriça”, em Sharing etbical principles through cultural diversity: Translations of the Montreal Statement on Research Integrity in Cross-Boundary Research Collaborations. Acesso em: 03 dez. 2018. https://wcrif.org/documents/356-iapg-translations-montreal-statment/file

Yale College. 1828. Reports on the Course of Instruction in Yale College. New Haven: Hezekiah Howe. Acesso em: 03 dez. 2018.

https://ia600309.us.archive.org/35/items/reportsoncourseo07yale/reportsoncourseo07yale.pdf

Yank, Veronica y Drummond Rennie. 1999. "Disclosure of researcher contributions: a study of original research articles in The Lancet". Annals of Internal Medicine 130: 661-670. http://doi.org/10.7326/0003-4819-130-8-199904200-00013

Zuckerman, Harriet A. 1968. "Patterns of name ordering among authors of scientific papers: a study of social symbolism and its ambiguity". The American Journal of Sociology 74 (3): 276-291. Acesso em: 10 abr. 2019.

http://www.jstor.org/stable/2775535 
Para citar este texto:

Lima, Juliana Soares y Maria Giovanna Guedes Farias. 2020. “Autoria em produções científicas: critérios, integridade na pesquisa e responsabilidade na colabocação". Investigación Bibliotecológica: archivonomia, bibliotecología e información 34 (82): 103-139.

http://dx.doi.org/10.22201/iibi.24488321xe.2020.82.58068 
Anexo A

Quadro de definições, critérios e ordem de autoria

\begin{tabular}{|c|c|c|c|}
\hline Entidade & Definição & Critérios & Ordem de autoria \\
\hline $\begin{array}{l}\text { American } \\
\text { Psychological } \\
\text { Association } \\
\text { (APA) }\end{array}$ & $\begin{array}{l}\text { - A autoria é reservada } \\
\text { para pessoas que } \\
\text { fazem uma contribuição } \\
\text { substancial e aceitam a } \\
\text { responsabilidade por um } \\
\text { trabalho publicado. } \\
\text { - Os indivíduos devem } \\
\text { ter autoria reconhecida } \\
\text { por trabalhos que } \\
\text { realmente realizaram ou } \\
\text { para os quais contribuí- } \\
\text { ram significativamente. } \\
\text { Portanto, a autoria } \\
\text { engloba não apenas } \\
\text { aqueles que de fato } \\
\text { redigem, mas também } \\
\text { aqueles que fizeram } \\
\text { contribuições científicas } \\
\text { significativas para um } \\
\text { estudo. }\end{array}$ & 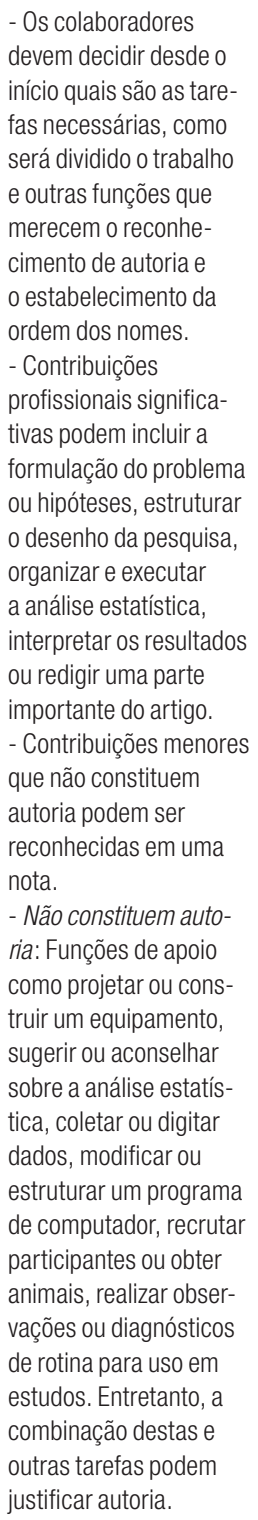 & $\begin{array}{l}\text { - Os autores são } \\
\text { responsáveis pela } \\
\text { determinação da autoria } \\
\text { e pela especificação da } \\
\text { ordem em que os nomes } \\
\text { de dois ou mais autores } \\
\text { aparecem na linha de } \\
\text { autores. } \\
\text { - A regra geral é que o } \\
\text { nome do principal cola- } \\
\text { borador deve aparecer } \\
\text { primeiro, seguido dos } \\
\text { outros nomes em ordem } \\
\text { de contribuição. } \\
\text { - Se os autores tiveram } \\
\text { papéis idênticos na } \\
\text { pesquisa e na publi- } \\
\text { cação, podem indicar } \\
\text { isso na nota do autor. } 0 \\
\text { status (chefe, professor, } \\
\text { estudante) não deve } \\
\text { determinar a ordem de } \\
\text { autoria. } \\
\text { - As normas da APA tam- } \\
\text { bém estabelecem que } \\
\text { os alunos de mestrado e } \\
\text { doutorado merecem au- } \\
\text { toria principal em seus } \\
\text { originais dependendo de } \\
\text { suas contribuições. }\end{array}$ \\
\hline
\end{tabular}




\begin{tabular}{|c|c|c|c|}
\hline Entidade & Definição & Critérios & Ordem de autoria \\
\hline $\begin{array}{l}\text { American } \\
\text { Physical } \\
\text { Society } \\
\text { (APS) }\end{array}$ & $\begin{array}{l}\text { - A autoria deve ser } \\
\text { limitada àqueles } \\
\text { que contribuíram } \\
\text { significativamente } \\
\text { para o conceito, } \\
\text { desenho, execução } \\
\text { ou interpretação do } \\
\text { estudo de pesquisa. } \\
\text { Todos aqueles que } \\
\text { fizeram contribuições } \\
\text { significativas devem } \\
\text { ter a oportunidade de } \\
\text { serem listados como } \\
\text { autores. Outros indiví- } \\
\text { duos que contribuíram } \\
\text { para o estudo devem } \\
\text { ser reconhecidos, mas } \\
\text { não identificados co- } \\
\text { mo autores. As fontes } \\
\text { de apoio financeiro } \\
\text { para o projeto devem } \\
\text { ser divulgadas }\end{array}$ & 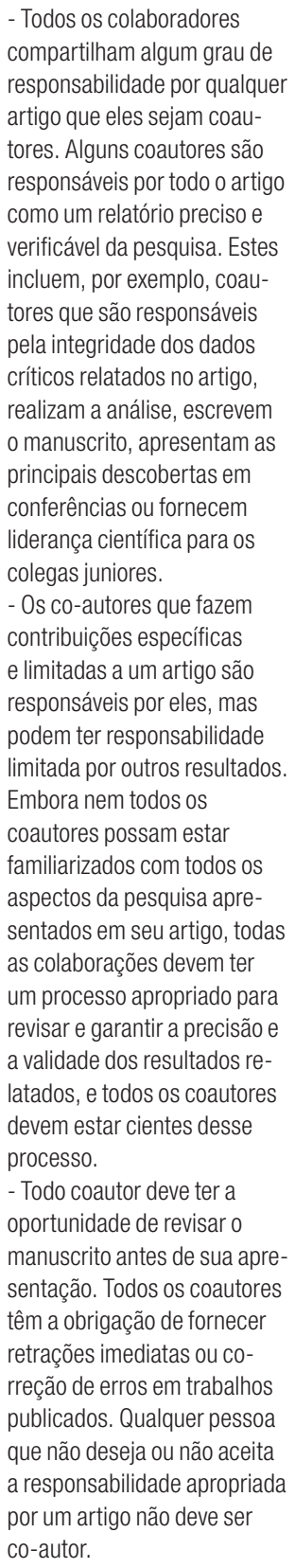 & $\begin{array}{l}\text { - Não estabelece } \\
\text { critérios ou prescrições } \\
\text { para a ordem de } \\
\text { autoria }\end{array}$ \\
\hline
\end{tabular}




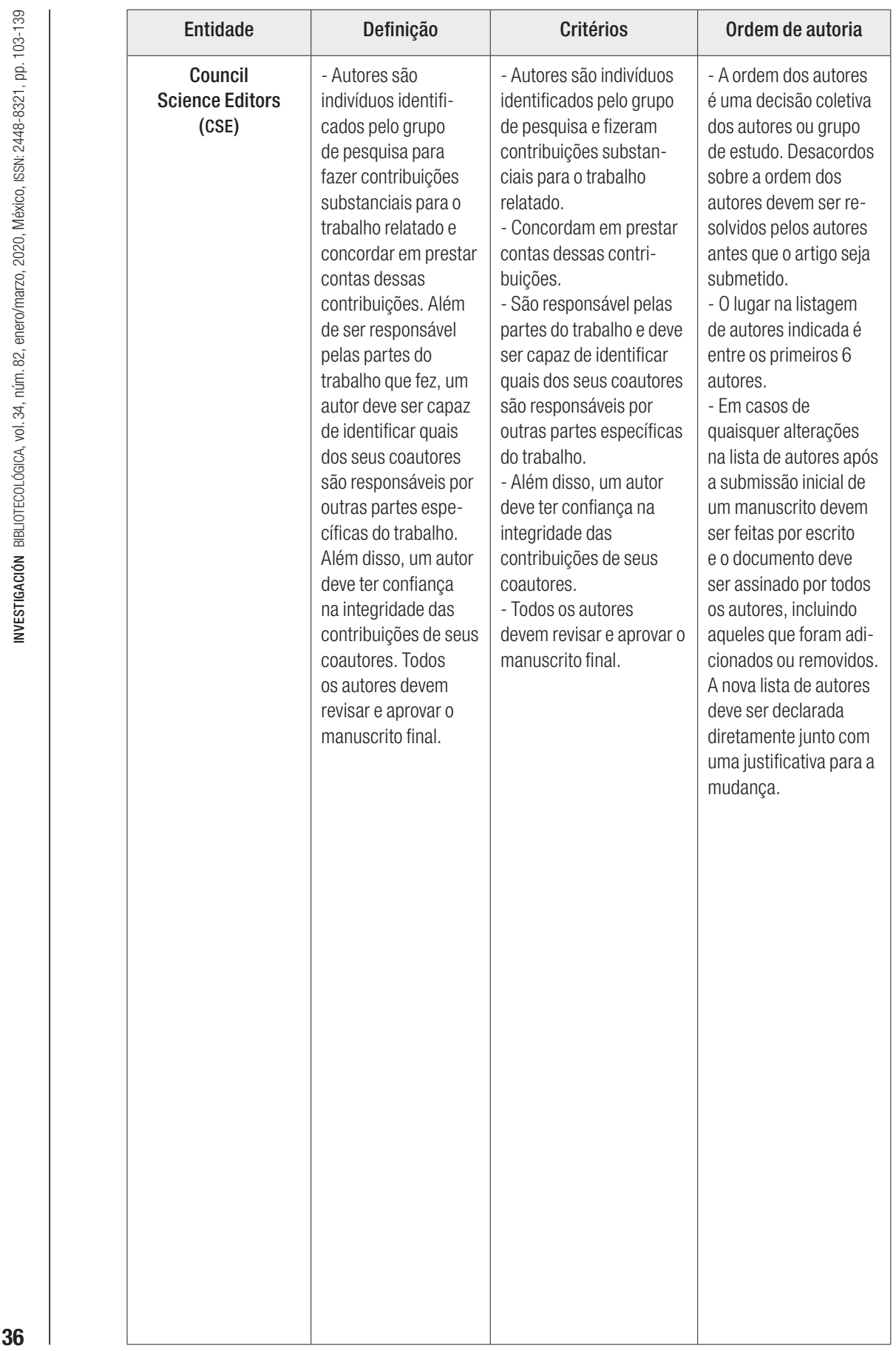




\begin{tabular}{|c|c|c|c|}
\hline Entidade & Definição & Critérios & Ordem de autoria \\
\hline $\begin{array}{l}\text { International } \\
\text { Committee } \\
\text { of Journal Editors } \\
\text { (ICMJE) }\end{array}$ & 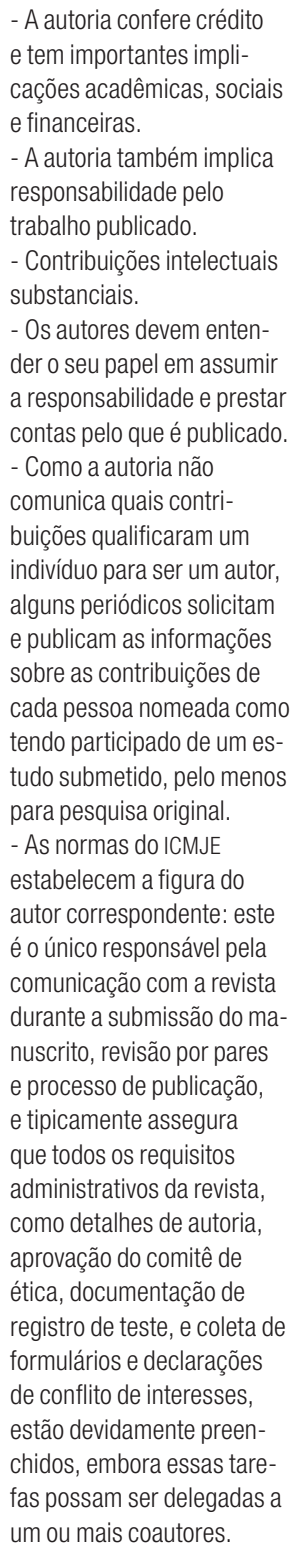 & $\begin{array}{l}\text { - Contribuições } \\
\text { substanciais para a } \\
\text { concepção ou desenho } \\
\text { do trabalho; ou a } \\
\text { aquisição, análise ou } \\
\text { interpretação de dados } \\
\text { para o trabalho. } \\
\text { - Elaborar o trabalho e } \\
\text { revisá-lo criticamente } \\
\text { em relação ao conteú- } \\
\text { do intelectualmente } \\
\text { importante. } \\
\text { - Aprovação final da } \\
\text { versão a ser publicada. } \\
\text { - Concordância em } \\
\text { ser responsável por } \\
\text { todos os aspectos do } \\
\text { trabalho, assegurando } \\
\text { que as questões rela- } \\
\text { cionadas à precisão ou } \\
\text { integridade de qualquer } \\
\text { parte do trabalho sejam } \\
\text { devidamente investiga- } \\
\text { das e resolvidas. } \\
\text { - Os colaboradores } \\
\text { que não atenderem } \\
\text { aos quatro critérios de } \\
\text { autoria do ICMJE não } \\
\text { devem ser listados } \\
\text { como autores, mas } \\
\text { devem ser reconhe- } \\
\text { cidos por meio de } \\
\text { agradecimentos. }\end{array}$ & $\begin{array}{l}\text { - Quando um grande } \\
\text { grupo de autores } \\
\text { conduziu o trabalho, } \\
\text { o grupo deve decidir } \\
\text { quem será autor prin- } \\
\text { cipal antes do início do } \\
\text { trabalho, e, confirmar } \\
\text { quem é o autor antes } \\
\text { de enviar o manuscrito } \\
\text { para publicação. } \\
\text { - Todos os membros } \\
\text { do grupo nomeados } \\
\text { como autores devem } \\
\text { atender a todos os } \\
\text { quatro critérios de } \\
\text { autoria, incluindo a } \\
\text { aprovação do manus- } \\
\text { crito final. }\end{array}$ \\
\hline
\end{tabular}




\begin{tabular}{|c|c|c|c|}
\hline Entidade & Definição & Critérios & Ordem de autoria \\
\hline $\begin{array}{l}\text { Office of Research } \\
\text { Integrity } \\
\text { (USA) }\end{array}$ & $\begin{array}{l}\text { - A autoria geralmente } \\
\text { é limitada a indivíduos } \\
\text { que fazem contribuições } \\
\text { significativas para o trabalho } \\
\text { relatado. }\end{array}$ & $\begin{array}{l}\text { - Envolveu-se intima- } \\
\text { mente na concepção e } \\
\text { design da pesquisa. } \\
\text { - Assumiu a respon- } \\
\text { sabilidade pela coleta } \\
\text { e interpretação de } \\
\text { dados. } \\
\text { - Participou na elabo- } \\
\text { ração da publicação. } \\
\text { - Aprovou a versão final } \\
\text { da publicação. }\end{array}$ & $\begin{array}{l}\text { - Autores são listados } \\
\text { em sua ordem de } \\
\text { importância, com a } \\
\text { designação de primei- } \\
\text { ro ou último autor com } \\
\text { peso especial, embora } \\
\text { as práticas variem por } \\
\text { disciplina. } \\
\text { - Algumas instituições } \\
\text { acadêmicas não pro- } \\
\text { movem pesquisadores } \\
\text { para o posto de profes- } \\
\text { sores efetivos até que } \\
\text { estes tenham sido } \\
\text { listados como primeiro } \\
\text { ou último autor em um } \\
\text { ou mais artigos. }\end{array}$ \\
\hline
\end{tabular}

Exemplos de entidades profissionais que adotam definições, critérios e ordem de autoria Fonte: elaborado pelas autoras (2019)

\section{Anexo B \\ Autoria e padrões de área (lista de sites institucionais)}

- American Anthropological Association (AAA): http://www.americananthro.org/StayInformed/Content.aspx?ItemNumber=2044

- American Physical Society (APS): https://www.aps.org/policy/statements/02_2.cfm

- American Psychological Association (APA): https://www.apastyle.org/ about-apa-style

- American Sociological Association (ASA): http://www.asanet.org/ teaching-learning/faculty/teaching-ethics-throughout-curriculum/topic-authorship-credit

- Association of Legal Writing Directors (ALWD) Guide to Legal Citation: https://www.alwd.org/publications/citation-manual/

- Basic Legal Citation, do Legal Information Institute, na Cornell University Law School: https://www.law.cornell.edu/citation/toc

- International Committee of Medical Journal Editors (ICMJE): http:// www.icmje.org/recommendations/

- The Indigo Book: A Manual of Legal Citation: https://law.resource. org/pub/us/code/blue/IndigoBook.html 
- The Office of Research Integrity: https://ori.hhs.gov/publicationsauthorship

- White Paper on Publication Ethics (CSE): https://www.councilscienceeditors.org/resource-library/editorial-policies/white-paper-on-publication-ethics/ 